\title{
Hibridez em tempos de pandemia: como as tecnologias aproximam as bibliotecas da sociedade
}

\author{
Hybridity in pandemic times: how technologies bring libraries \\ closer to society
}

\author{
Rosângela Formentini Caldas ${ }^{a}$ (10) \\ Rafaela Carolina da Silva ${ }^{a, *}$ (i)
}

\begin{abstract}
RESUMO: A proposta foi levantar os meios de atuação das bibliotecas públicas no isolamento social, face à pandemia do Covid-19 no Brasil. Questionou-se como as bibliotecas públicas estaduais brasileiras, por meio de seus produtos e serviços, se adequaram às novas instruções de enfrentamento ao vírus neste momento de isolamento social, a fim de oferecem às suas comunidades um suporte informacional que proporcionasse melhores meios de lazer, informações de saúde e acesso a profissionais qualificados. Mediante o contexto vivenciado e as necessidades do uso da tecnologia, enfatizou-se a hibridez como uma forma de gestão nestes ambientes. A abordagem foi qualitativa, do tipo exploratória. O método utilizado foi a pesquisa documental e a coleta de dados alcançou o site do Sistema Nacional de Bibliotecas Públicas (SNBP) e as bibliotecas pertencentes ao Sistema das Secretarias Estaduais de Cultura. Observouse que as regiões sul e sudeste foram as que, inicialmente, apresentaram diretrizes de combate ao Covid19 no Brasil e, portanto, fizeram parte da amostragem desta pesquisa. Em se tratando de um novo fenômeno social mundial para enfrentamento de uma pandemia foi preciso compreender a atual gestão de bibliotecas públicas, de modo a proporcionar a troca de informações entre instituições e sociedade. Nessa perspectiva, a habilidade de atuação com o processo da hibridez trouxe subsídios imprescindíveis aos modos de atuação remota das bibliotecas analisadas. O SNPB foi destaque no oferecimento de diretrizes e as bibliotecas utilizaram meios de atividades diversificadas de entretenimento e acesso à comunicação e informação, de modo a tornarem-se partícipes das necessidades atuais da sociedade.
\end{abstract}

Palavras-chave: Hibridez em Bibliotecas; Bibliotecas Públicas; Covid-19; Desenvolvimento de Comunidades.

ABSTRACT: The propose of the study was to survey the Brazilian public libraries activities, in view of the Covid-19 pandemic. More specifically, the objective was to define the products and services that these libraries are offering to their communities, emphasizing the hybridity as a way of managing environments. The approach is qualitative, and exploratory. The method was the Documentary Research, which comprised the website of the National System of Public Libraries (SNBP), as well as the website of the libraries who participated of the study. The Brazilian south and southeast regions were those that first presented these guidelines, hence are part of the research sample. Facing the new social context in the world, it is necessary to understand the current management of public libraries, to provide the exchange of information between institutions and society. In the case of a new global social phenomenon, in order to face a pandemic, it was necessary to understand the current management of public libraries, in order to provide the exchange of information between institutions and society. In this perspective, the ability to act with the hybridity process, brought indispensable subsidies to the modes of remote action of the analyzed libraries. Such localities used diversified means of entertainment activities and access to communication and information, to become participants in the current needs of society.

Keywords: Hybridity in Libraries; Public Libraries; Covid-19; Development of Communities.

\footnotetext{
a Programa de Pós-Graduação em Ciência da Informação, Universidade Estadual Paulista "Júlio de Mesquita Filho", Marília, SP, Brasil.

*Correspondência para/Correspondence to: Rafaela Carolina da Silva. E-mail: rafaela.c.silva@unesp.br. Faculdade de Filosofia e Ciências, Universidade Estadual Paulista, 17525-900, Marília, São Paulo, SP, Brasil.
}

Recebido em/Received: 15/08/2020; Aprovado em/Approved:16/10/2020.

Artigo publicado em acesso aberto sob licença CC BY 4.0 Internacional cC) 


\section{INTRODUÇÃO}

Nos primeiros meses do ano de 2020 nos deparamos com o inimaginável, até então, em nosso cotidiano: o isolamento social. Ficamos atônitos, perplexos e desnorteados frente aos noticiários que chegavam em nossos lares, advindos de todos os países, em uma ordem mundial. Notícias aterrorizantes de mortes, de hostilidades sociais, de fechamento de empresas e comércio sugeriram que devíamos, efetivamente, tomar cuidado. Pessoas perderam seus empregos, os governos careciam, imediatamente, de adotar ações no campo da saúde e nós passamos a cuidar, inclusive, da informação, que deveria vir de uma fonte fidedigna, pois com a crescente e incerta busca informacional, nos trouxe as fakes news.

Os dias, repletos de preocupações cotidianas, chegaram até a parecerem tranquilos, e cederam o lugar para a instalação de uma pandemia ocasionada por um vírus denominado novo coronavírus, ou Covid-19. Passamos, então, a perceber que deveríamos seguir as determinações das agências de saúde pelo direito à vida. Os governos mundiais solicitavam o apoio da sociedade para a compreensão de que o único meio de não difundir o vírus seria o isolamento social.

O isolamento social foi imposto por vários países como meio de controle do vírus Covid-19, que poderia ser letal, sem meios testados e comprovados para impedir a sua propagação. Isolados em nossas residências, precisávamos de instituições sérias que pudessem fornecer, numa adaptação rápida e precisa, informação de qualidade e atividades a serem realizadas com os meios disponíveis nas residências dos indivíduos e que contemplassem todas as faixas etárias.

Assim, as bibliotecas, enquanto instituições que prezam pelo acesso informacional a toda a sociedade, sem intervalos, procuraram se reinventar e passaram a entender o atual momento de isolamento social como uma oportunidade de oferta de novos produtos e serviços, adaptados a uma sociedade que atravessava uma pandemia.

A hibridez, tema muito discutido nas décadas que se seguiram entre 1980 e 2000, mas, com escassa publicação, atualmente deu lugar à sua aplicação nas bibliotecas públicas, tornando-se fator diferencial de aplicabilidade. Uma biblioteca híbrida trabalha "o amplo compartilhamento de recursos, em entidades geograficamente dispersas, como às relações humanas, tecnológicas e sociais de uma determinada instituição" (SILVA, 2017, p. 163). Portanto, há uma convergência entre as ferramentas tecnológicas, o fazer profissional diversificado e o usuário enquanto sujeito, não mais utilitário da informação, mas, cooperante no seu uso, produção e acesso, o que promove a inclusão social de toda a comunidade organizacional.

Levando-se em conta os seguintes questionamentos: "Quais são as formas de atuação das bibliotecas públicas brasileiras, frente as medidas de isolamento necessárias para travar a propagação do novo coronavírus?" e "Como a hibridez pode subsidiar as atividades a serem desenvolvidas pelas bibliotecas públicas em tempos de pandemia?", procurou-se responder ao seguinte problema de pesquisa: "Utilizando-se o conceito de bibliotecas híbridas, qual a possibilidade da hibridez atuar como meio de aproximação entre pessoas e de disseminação da informação na integração social em bibliotecas públicas?".

Acredita-se que a hibridez poderia trazer subsídios aos modos de atuação remota de bibliotecas públicas, o que contribuiria para a informatização da população em época de Covid-19. Se o acesso à informação é primordial ao desenvolvimento de comunidades, logo, os produtos e serviços oferecidos por essas bibliotecas em tempos de pandemia devem ser repensados. 
A hipótese levantada é a de que, considerando-se o contexto de isolamento social advindo das medidas de proteção contra o novo coronavírus, bem como o entendimento de que as comunidades de usuários estão vivenciando uma pressão psicológica constante, a atuação híbrida em bibliotecas públicas pode trazer benefícios à saúde mental dos indivíduos, na medida em que, além de promover o acesso à informação, trabalha com atividades que, ao entretê-los, podem desfocá-los, por algum tempo, da intimidação causada pela realidade pandêmica à qual o mundo se depara. Logo, é importante que as bibliotecas públicas assegurem suas atividades de maneira remota, a fim de colaborarem na produção e na disponibilização de recursos informacionais para a população e, assim, manterem suas comunidades atentas, alertas e informadas.

A proposta do estudo procurou levantar os meios de atuação das bibliotecas públicas no isolamento social, face à pandemia do Covid-19, no Brasil. Mais especificamente, delimitar os produtos e os serviços que uma amostragem dessas bibliotecas está oferecendo às suas comunidades, enfatizando a hibridez como uma forma de gestão nesses ambientes.

O método utilizado foi a pesquisa documental e os instrumentos de coleta de dados alcançaram o site do Sistema Nacional de Bibliotecas Públicas (SNBP), atuante em articulação e parceria com 27 Sistemas Estaduais de Bibliotecas Públicas (SEBPs), a fim de fortalecer as ações de estímulo ao livro, à leitura e às bibliotecas. Por meio das Secretarias Estaduais de Cultura, selecionou-se os websites das instituições participantes.

Observou-se que as regiões sul e sudeste foram as que, inicialmente, apresentaram diretrizes de combate ao Covid-19 no Brasil e, portanto, fizeram parte da amostragem desta pesquisa. Em se tratando de um novo fenômeno social mundial para enfrentamento de uma pandemia, foi preciso compreender a atual gestão de bibliotecas públicas, de modo a proporcionar a troca de informações entre instituições e sociedade.

Em se tratando do novo cenário social ao qual o mundo se depara, é preciso compreender a atual gestão de bibliotecas públicas, de modo a proporcionar a troca de informações entre instituições no que se refere ao compartilhamento de ideias acerca de como trabalhar, de forma híbrida, em épocas de pandemia. Nessa perspectiva, a hibridez vem trazer subsídios aos modos de atuação remota em bibliotecas.

\section{BIBLIOTECAS PÚBLICAS}

De acordo com o Manifesto da International Federation of Library Associations and Institutions (IFLA) e da Organização das Nações Unidas para a Educação, a Ciência e a Cultura (UNESCO, 1994), a biblioteca pública é uma porta de acesso ao conhecimento, pois, fornece as condições básicas para a aprendizagem ao longo da vida, independentemente da cultura dos indivíduos e de seus grupos sociais. Nessa perspectiva, tal instituição se caracteriza por ser um centro local de informação, tornando o conhecimento de todos os gêneros acessível aos seus utilizadores.

Dito isso, os serviços das bibliotecas públicas devem se basear na igualdade de acesso, sem distinção de raça, sexo, religião, nacionalidade, língua ou condição social, atingindo todos os grupos etários de uma comunidade. Para a IFLA/UNESCO (1994), as coleções e os serviços dessas instituições devem incluir os diversos tipos de suporte de informação, do analógico ao digital, de modo a se adequarem às necessidades locais. 
Desse modo, as coleções das bibliotecas públicas precisam estar em consonância com as transformações advindas da sociedade.

Vale destacar que o termo "público", para o cenário das bibliotecas, segundo Keinart (2000), transforma esse espaço em um local de ações coletivas e cotidianas, com suporte financeiro do Estado, o que evidencia a tese de que todas as pessoas, nessas localidades, devem possuir acesso à informação. O público, então, é resultado do entrelaçamento Estado-Sociedade, contando que tais organizações são mantidas, além do Estado, por pessoas, coletivos e instituições privadas, ou sem fim lucrativos, comprometidas com as suas comunidades. Tendo em vista esse cenário, o Manifesto sobre Transparência, desenvolvido pela IFLA (2008), afirma o papel social da biblioteca pública na transparência dos governos e no acesso à informação, já que, por ser uma instituição mantida pelo governo, ampliam-se as concepções de sua atuação para tal organização.

Segundo Almeida Júnior (1997), a função da biblioteca pública é levar a informação para a sua comunidade de usuários, visando, por meio da leitura, a construção da cidadania, além de possibilitar o conhecimento dos direitos sociais a todos os cidadãos. Isto posto, o papel primordial dessa instituição está na democratização do acesso à informação, na medida em que promove atividades para a população, independentemente da sua classe social, sexo, orientação sexual ou religião. Logo, seus serviços e produtos são alocados para atender às funções a ela atribuídas, essas advindas das apropriações que os usuários fazem na interação com o conhecimento por ela compartilhado (FREITAS; REGEDOR, 2007).

Nesse panorama, pode-se dizer que a biblioteca pública é, na sociedade, o somatório de suas funções e da oferta de produtos e serviços necessários para as suas comunidades (BERNARDINO; SUAIDEN, 2011). Dessa maneira, o objetivo da biblioteca pública é oferecer serviços de acesso à informação, por meio da promoção de atividades que ampliem o pensar do indivíduo, como produtos culturais e artísticos, memória e identidade local. Consequentemente, tais bibliotecas se caracterizam por serem instituições sociais, pois, se servem a propósitos sociais, como cultura, memória, educação e lazer.

Atualmente, vivemos num momento em que as bibliotecas têm que modificar toda a sua estrutura, incluindo produtos e serviços para promover atendimento à distância para os usuários. Nesse cenário, destacam-se as bibliotecas híbridas, que serão melhor trabalhadas na próxima seção deste artigo.

\section{BIBLIOTECAS HÍBRIDAS}

De acordo com Orera-Orera e Pacheco (2017), em países como a Espanha, as bibliotecas híbridas se caracterizam por serem novos modelos de bibliotecas, surgidas na chamada Sociedade da Informação e do Conhecimento, e representam o predomínio das novas tecnologias, a globalização e o volume cada vez maior de informação em formato eletrônico. Nessa perspectiva, Orera-Orera (2007) defende que quando o conceito de biblioteca passa a ser constantemente revisado, acompanhando o processo evolutivo das mudanças sociais, surgem as bibliotecas híbridas.

Weber (2004) destaca que, em contexto alemão, as bibliotecas híbridas promovem o acesso à informação tradicional, baseada em papel, bem como a recursos mediados eletronicamente. Em vista disso, a biblioteca híbrida pode ser caracterizada para além 
de uma entidade física real, convergindo recursos para atender às necessidades de aprendizagem de seus usuários.

A biblioteca híbrida, na França, está ligada ao conceito de mediação cultural, isto é, à convergência "[...] de práticas oriundas de diferentes universos que vão desde as práticas tradicionais de animação social e da educação popular à nova "gestão" cultural e sociológica, através da história da arte e da interpretação (guiada) das obras" (FONTAN, 2007, p. 8, grifo do autor, tradução nossa). Isto posto, as bibliotecas híbridas, para mais de integrarem recursos de informação impressos e eletrônicos, intervém em esferas sociais, políticas, econômicas e culturais da sociedade, buscando responder às necessidades ou desejos, individuais ou coletivos, de suas comunidades.

Em países como os Estados Unidos, existe o trabalho dos, como Baker (2013) denomina, conservadores híbridos, ou bibliotecários híbridos, profissionais que antecipam a produção e a organização de suas diversas coleções, de acordo com as necessidades informacionais dos usuários e das políticas institucionais da organização, convergindo, em um mesmo acervo, diferentes temáticas, tipos de suportes e recursos informacionais. Portanto, na biblioteca híbrida, há “[...] uma ampla gama de novos e interessantes trabalhos para o pessoal, independentemente de sua formação educacional" (FIND, 1999, s.p., tradução nossa), havendo o profissional da informação, enquanto bibliotecário híbrido, que saber como trabalhar com a informação registrada em diferentes mídias.

O papel das bibliotecas híbridas, em âmbito brasileiro, é "[...] identificar pequenos grupos de usuários e oferecer serviços mais especializados de valor agregado, com grande flexibilidade e criatividade em sua realização e forma, por meio do diagnóstico do que o usuário deseja, realizado de uma forma continuada" (GARCEZ; RADOS, 2002, p. 46). Desse modo, entende-se que as bibliotecas híbridas agregam diferentes tecnologias e fontes de informação, convergindo produtos e serviços que se utilizam de tecnologias como ferramentas estratégicas para unir a melhor parte do cenário dos recursos impressos, bem como do meio digital. Logo, a estrutura da biblioteca híbrida “[...] entrelaça todos os conceitos em um único pensamento, e cria uma nova versão de biblioteca, que se utiliza das tecnologias e usufrui de um acervo digital, mas também mantém o formato tradicional ao disponibilizar um acervo físico" (CAVALCANTE; BRITO; VLAXIO, 2016, p. 48).

Tendo em vista esse cenário, a ideia de bibliotecas híbridas “[...] parte de uma visão extensionista do conceito de bibliotecas, nas quais, por meio do conhecimento construído, exige-se o exercício da cidadania" (SILVA et al. 2018, p. 406). Ao se trabalhar com as bibliotecas híbridas é preciso levar em conta sua arquitetura, serviços e produtos oferecidos, relações sociais, design da informação, convergência de linguagens, aprender a aprender ao longo da vida, melhoria futura, funcionários, usuários, coleção, design interno, design externo, gerenciamento local da informação e gerenciamento externo da informação.

Para Silva, Jorente e Caldas (2017, p. 278), nas bibliotecas híbridas existe "[...] uma maior dialogicidade dos produtos e serviços, uma vez que há uma convergência de mídias tecnológicas e de linguagens". Nesse contexto, os processos tradicionais desempenhados pela biblioteca passam a contar com diversos tipos e formatos de tecnologias informacionais, sendo esses uma complementação das mídias digitais às mídias tradicionais. 


\section{METODOLOGIA}

O estudo caracterizou por ser de natureza qualitativa, do tipo exploratória. O método de pesquisa utilizado foi a pesquisa documental. Participaram do universo de pesquisa as instituições SNPB e as Secretaria Públicas Estaduais de Cultura, por meio da representatividade de suas bibliotecas. $O$ instrumento de coleta de dados foi a planilha que integralizou informações do website do SNBP, bem como dos sites das Secretarias Estaduais de Cultura dos Estados das regiões sul e sudeste. Entendeu-se, dessa forma, que as informações coletadas seriam oficiais.

Tendo em vista que a pesquisa documental serve a estudos elaborados para busca de informações em documentos históricos, associativos, oficiais, dentre outros, a fim de se desenvolver uma análise científica dos mesmos (GIL, 2008), em um primeiro momento, delimitou-se a pesquisa ao site do SNBP. A busca realizada no website recorreu às notícias publicadas pelo SNBP acerca das ações de bibliotecas públicas perante a pandemia Covid-19. Para tanto, inseriu-se, no campo "busca", no link notícias, os descritores bibliotecas AND coronavírus OR "covid-19".

Percebendo-se que, em âmbito nacional, as instituições analisadas estavam trabalhando com diretrizes de atuação em bibliotecas estaduais, focou-se nas iniciativas, por Estado, das atividades desenvolvidas em bibliotecas públicas. Nesse segundo momento de pesquisa foi possível observar que as regiões sul e sudeste foram as que, inicialmente, apresentaram diretrizes de combate ao Covid-19 no Brasil e, portanto, os resultados deste estudo se referiram a uma amostragem da atuação das bibliotecas dessas regiões em seus Estados. Para a coleta dos dados, os pesquisadores adentraram, nos meses de abril, maio, junho, julho e meados de agosto de 2020 os sites das Secretarias Estaduais de Cultura desses Estados, assim como as páginas de cada instituição participante do estudo, em busca de publicações que tratassem do assunto.

\section{ANÁLISE DE DADOS}

O levantamento de dados no site do SNBP trouxe resultados relacionados à atuação das bibliotecas públicas da regiões sul e sudeste brasileiras, não refletindo a situação brasileira como um todo. Importante destacar que esses resultados trabalharam, em essência, com diretrizes gerais para a atuação das bibliotecas em tempos de Covid-19. Tais diretrizes se basearam nas premissas da American Library Association (ALA, 2020) e IFLA (2020), da Organização das Nações Unidas para a Educação, a Ciência e a Cultura (UNESCO 2020) e da Organização Mundial da Saúde (OMS, 2020) no combate à pandemia Covid-19 em unidades de informação.

Assim, foi possível observar a atuação da Agência da Universidade de São Paulo (USP) para a Gestão da Informação Acadêmica (2020), que apresentou um projeto sobre a limpeza, higienização e desinfecção de bibliotecas. A mesma corrente de pensamento foi percebida nas publicações da Biblioo Carta Capital (2020), de Marquina (2020), do Ministério da Saúde (2020), do Grupo de Informação e Documentação Jurídicas do Distrito Federal (2020), do Instituto Brasileiro de Informação em Ciência e Tecnologia (IBICT, 2020) e da Biblioteca do Senado Federal (2020). Com destaque nacional e internacional, o SNBP (2020) publicou um ofício com orientações para as bibliotecas públicas e comunitárias contra o Covid-19. Além disso, o Conselho Regional de Biblioteconomia, oitava região (CRB-8), sudeste do Brasil, trabalhou com diretrizes para a salvaguarda de acervos em bibliotecas (CONSELHO REGIONAL DE BIBLIOTECONOMIA 2020). 
As diretrizes levantadas nesses projetos giravam em torno de seis ideais, a serem levados em conta na atuação de profissionais da informação. A saber: 1. separar uma estante para recebimento do material devolvido; 2. receber os materiais dos empréstimos com luvas; 3. acomodar o material recebido em estante separada para tal fim; 4. não colocar o material devolvido no acervo durante cinco dias, bem como não liberá-lo para empréstimo durante esse período; 5 . higienizar as mãos com água, sabão e álcool em gel; e 6. após seis dias de recebimento do material emprestado, e usando equipamento de proteção individual, higienizar a capa dos itens com álcool e papel toalha e, só assim, liberá-lo novamente para empréstimo (CONSELHO REGIONAL DE BIBLIOTECONOMIA, 2020; SISTEMA NACIONAL DE BIBLIOTECAS PÚBLICAS, 2020; BIBLIOTECA DO SENADO FEDERAL, 2020).

Algumas outras dicas também foram ressaltadas, como o oferecimento de treinamento cruzado, para que profissionais diversificados pudessem assumir o trabalho dos funcionários que viessem a ficar doentes; o mantimento de políticas para distanciamento social (remoção de cadeiras no salão de leitura, para que não haja possibilidade de os usuários se sentarem próximos uns aos outros; bem como limitação do número de pessoas que venham a adentrar a instituição); a avaliação da possibilidade de suspensão de eventos e outros programas da biblioteca; o fornecimento de máscaras e luvas a funcionários e público, juntamente com o treinamento do pessoal; e o desenvolvimento de novos serviços de informação, como pedidos online de materiais a usuários (GRUPO DE INFORMAÇÃO E DOCUMENTAÇÃO JURÍDICAS DO DISTRITO FEDERAL, 2020; BIBLIOO, 2020). Para mais, foram sugeridas a adoção do teletrabalho; o uso de outro método de autenticação e abolição de uso de senhas, buscando evitar o contato das pessoas com máquinas eletrônicas de uso público; a suspensão do empréstimos entre bibliotecas, em função da restrição de acesso às instituições; a distribuição de cartazes educativos, solicitando que usuários com sintomas do vírus não frequentem o ambiente da biblioteca; e o pedido para que usuários consultem o catálogo antes de irem à instituição, de modo a diminuir a circulação desses entre as estantes (MINISTÉRIO DA SAÚDE, 2020; GRUPO DE INFORMAÇÃO E DOCUMENTAÇÃO JURÍDICAS DO DISTRITO FEDERAL, 2020; MARQUINA, 2020).

Tendo em vista tais diretrizes, pensou-se ser importante mostrar como as mesmas estão sendo aplicadas, na prática, em bibliotecas brasileiras. Com destaque para as regiões sudeste e sul, foram coletadas atividades de bibliotecas públicas nos Estados do Espírito Santo, Minas Gerais, Rio de Janeiro, São Paulo, Paraná, Rio Grande do Sul e Santa Catarina, regiões essas que se destacaram no desenvolvimento de programas e ações em prol do combate ao Covid-19 e, assim, delimitaram a amostragem desta coleta de dados. Cabe ressaltar o uso das tecnologias como meios de aproximação das atividades das bibliotecas em sociedade, bem como a atuação híbrida dessas localidades em suas comunidades.

O levantamento de dados mostrou que, no modo presencial, tais bibliotecas adotaram as medidas de proteção presencial contra o vírus mencionadas pelas organizações de saúde pública nacionais e internacionais. No que diz respeito às novas atividades desenvolvidas por essas instituições, essas se dividiram em 16 iniciativas. A saber: ampliação do número de empréstimos por pessoa (uma referência); ampliação do tempo de devolução de materiais (uma referência); oferecimento de cursos online (uma referência); sugestão de títulos e temas para leitura (uma referência); oferecimento de Quiz para descontração dos usuários (uma referência); renovação automática de empréstimos (uma referência); atendimento ao usuário via telefone / WhatsApp (duas referências); promoção de concursos com premiação (duas 
referências); entrega de recursos informacionais a domicílio / fora do ambiente da biblioteca (duas referências); atividades de contação de histórias online (duas referências); oferecimento atividades de Clube da leitura para discussão de textos (duas referências); abono de multas (duas referências); encontro entre bibliotecas, em prol de gerar discussões acerca da atuação dos profissionais da informação e usuários em tempos de Covid-19 (duas referências); proferimento de palestras (duas referências); lives (duas referências); bem como disponibilização de livros para acesso online (quatro referências).

O Gráfico 1 demonstra as atividades oferecidas pelas bibliotecas analisadas na amostragem deste estudo.

\section{Gráfico 1 - Atividades desenvolvidas pelas bibliotecas das regiões sul e sudeste do Brasil em tempos de Covid-19}

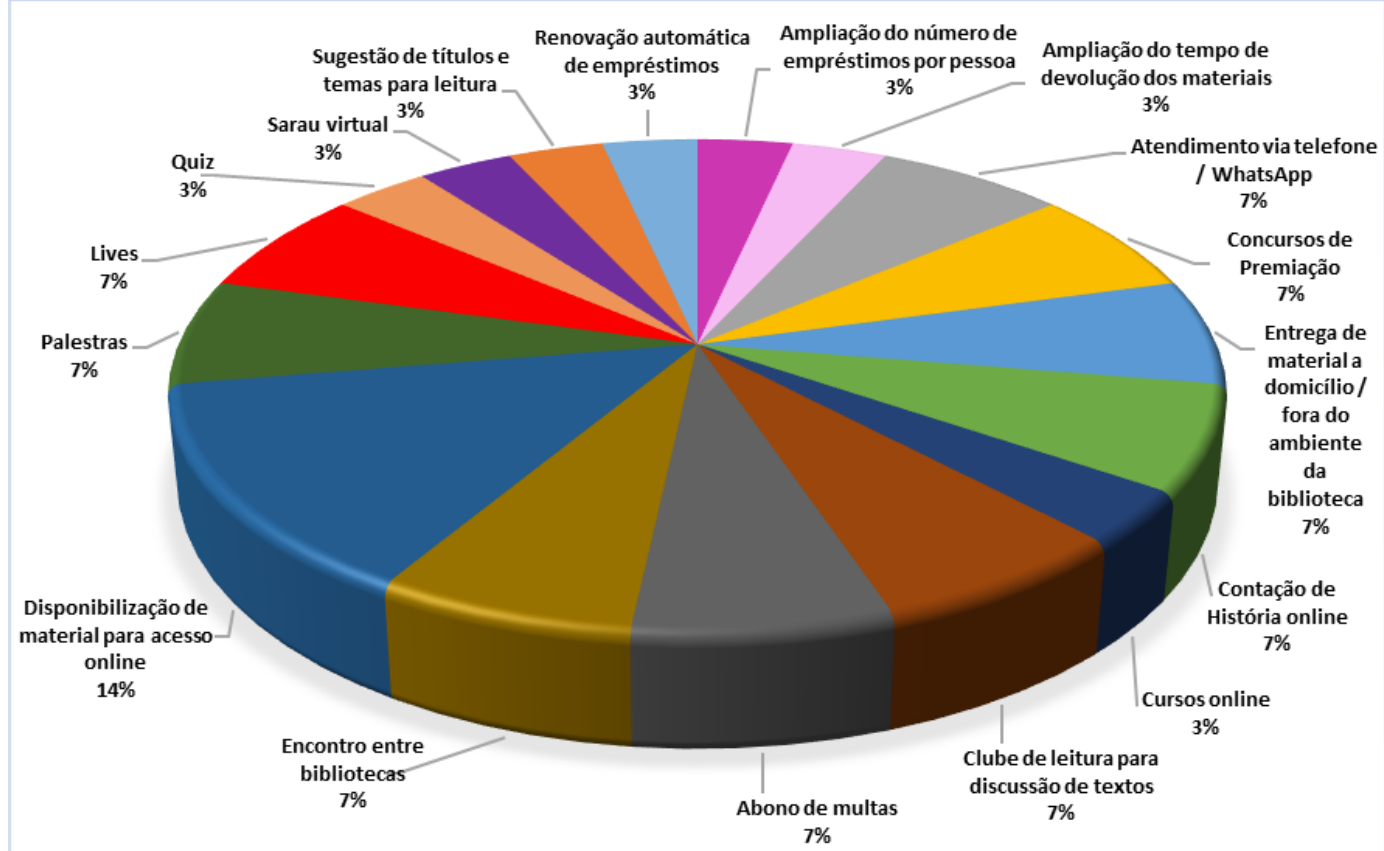

Fonte: Elaborado pelos autores.

Na região sudeste do Brasil, no que se refere ao Estado do Espírito Santo, o Sistema Estadual de Bibliotecas Públicas do Espírito Santo (SEBPES) realizou, por videoconferência, um Encontro Estadual de Bibliotecas Públicas Municipais, tendo como pautas principais as discussões sobre os seus procedimentos diante das medidas sanitárias e administrativas decorrentes da pandemia do novo coronavírus. Discutiuse, também, as orientações para o pós-pandemia (GOVERNO ESPÍRITO SANTO, 2020). Para mais, a Secretaria da Cultura do Estado do Espírito Santo lançou uma campanha de incentivo à leitura, denominada de Quarentena Literária (disponibilidade gratuita a e-books), onde os leitores de todo o Estado puderam compartilhar vídeos e dicas de leitura, bem como concorrerem a brindes relacionados à leitura e tecnologia (GOVERNO ESPÍRITO SANTO, 2020). Já a Biblioteca Pública Municipal de Linhares "Antônio Azevedo de Lima" resolveu tomar as precauções de isolamento social e funcionar apenas para empréstimo e devolução de livros (PREFEITURA DE LINHARES, 2020). 
No Estado de Minas Gerais destacou-se a Biblioteca Pública Estadual de Minas Gerais, localizada na cidade de Belo Horizonte. A instituição desenvolveu atividades como Quarentena Literária (com o intuito de amenizar os efeitos do distanciamento social, a iniciativa buscou valorizar o hábito da leitura para pessoas com 60 anos ou mais, por meio do oferecimento de um acervo digital com mais de 20 mil e-books); palestras, por videoconferência, para se discutir a saúde mental das pessoas que trabalham e atendem em bibliotecas públicas e comunitárias durante o período de distanciamento social; lives com escritores e transmissão ao vivo no Dia Nacional do Escritor; cursos gratuitos online sobre o surgimento do livro impresso; e leituras de contos online, transmitidas ao vivo pelo Instagram no Dia do Livro Infantil (ao todo, seis tramas infantis foram contadas, sendo que a atração foi transmitida de forma simultânea também pelas redes sociais do festival). Além do mais, a Biblioteca Pública Estadual de Minas Gerais passou a publicar um Quiz semanal em suas redes sociais, a fim de testar a memória e o conhecimento de seus visitantes (BIBLIOTECA PÚBLICA ESTADUAL DE MINAS GERAIS; 2020).

Ainda no Estado de Minas Gerais foi percebida uma iniciativa na Biblioteca Pública Professor Melo Cançado, Pará de Minas, que passou a reforçar sua segurança sanitária para atender melhor seus usuários. Ademais, a instituição promoveu uma campanha para explicar o seu novo jeito de funcionar pós-pandemia e, assim, atrair novamente os leitores até a localidade (RÁDIO SANTA CRUZ, 2020).

No Estado do Rio de Janeiro, as iniciativas observadas vieram da Prefeitura do Rio de Janeiro (2020), e não de uma biblioteca em específico. Desse modo, por meio da Gerência do Livro e Leitura da Secretaria Municipal de Cultural, deu-se continuidade a projetos como o Ônibus-biblioteca, disponibilizando, agora de forma virtual, livros em Portable Document Format (PDF) para o público infanto-juvenil. Ainda, criou-se o Sarau Virtual, onde há possibilidade de os autores declamarem textos autorais em vídeos e compartilhá-los com os leitores das bibliotecas municipais.

No Estado de São Paulo a maior parte das iniciativas advieram da Biblioteca de São Paulo (BSP, 2020), São Paulo Capital. A saber: Programa Leitura ao Pé do Ouvido, modalidade online (sugestão de títulos e temas para leitura); cursos online (literatura pré-vestibular); oficinas online (destinadas a empreendedores e negócios, cujo objetivo era mostrar como o vídeo é uma ferramenta poderosa de comunicação e marketing para o mundo digital); Clube da Leitura online, uma vez ao mês; Clube do Audiolivro online, uma vez ao mês (atividade indicada para jovens a partir de 11 anos); e projeto Segundas Intenções online (no qual a biblioteca traz um escritor para dissertar sobre determinado assunto) (BIBLIOTECA DE SÃO PAULO, 2020).

No caso da Biblioteca de Piracicaba "Ricardo Ferraz de Arruda Pinto", o atendimento ao público passou a ser realizado via telefone (BIBLIOTECA DE PIRACICABA, 2020). No mesmo sentido, a Biblioteca Municipal "Professor Nelson Foot", localizada na cidade de Jundiaí, concordou em abonar as multas dos empréstimos em atraso (BIBLIOTECA MUNICIPAL DE JUNDIAÍ, 2020).

Em relação ao sul do Brasil, o Estado do Paraná contou com a atuação da Biblioteca Pública do Paraná (BPP), Curitiba, em atividades de contação de história online, via YouTube, e em parcerias de fomento à produção e circulação de livros inéditos no formato de e-books. Para tanto, conjuntamente com o Governo do Paraná, a BPP lançou a primeira edição do Prêmio Biblioteca Digital, em que obras concorreram a prêmios em dinheiro (BIBLIOTECA PÚBLICA DO PARANÁ, 2020).

A Biblioteca Pública Municipal de Pinhais (2020) desenvolveu o projeto Livro em Casa, onde a instituição possibilitou ao usuário que tem cadastro no local fazer o empréstimo 
de até três livros, que Ihes seriam entregues, gratuitamente, em sua residência. Aqueles que não possuíssem cadastro poderiam enviar seus documentos para o e-mail da instituição, a fim de se associar à biblioteca.

Com o objetivo de despertar o gosto pela leitura, estimulando o potencial cognitivo e criativo das crianças, além de promover o desenvolvimento do vocabulário, diversificar o repertório de leitura e possibilitar produções orais e escritas durante o período da pandemia (BIBLIOTECA MUNICIPAL DE NOVA SANTA ROSA, 2020), a Biblioteca Pública Municipal "Doutor Arnaldo Faivro Busato", município de Nova Santa Rosa, desenvolveu o projeto "Semeando Leitura, colhendo leitores". Nele, foram entregues aproximadamente 300 sacolas de leitura personalizadas, feitas de tecido, para que os leitores do município pudessem transportar seus livros com maior cuidado.

No Estado do Rio Grande do Sul, a Biblioteca Pública do Estado, sediada em Porto Alegre, promoveu uma live, via Facebook, com especialistas da área da Ciência da Informação e da Saúde, acerca dos impactos da Covid-19 em bibliotecas e unidades de informação (BLIOTECAPUBLICADOESTADORS, 2020). A Biblioteca Pública de Erechim passou a seguir as recomendações da Organização Mundial da Saúde em suas ações, ou seja, a delimitar o atendimento presencial em apenas duas pessoas por vez. Essas só poderiam entrar no local com máscara e uso de álcool gel, além de manterem o distanciamento recomendado pelos órgãos de saúde (JORNAL DO COMÉRCIO, 2020). As medidas tomadas pela Biblioteca Pública Municipal "Doutor João Minssen", localizada em Cachoeira do Sul, foram: devoluções em dois turnos (manhã e tarde), respeitando o atendimento individual no balcão, com uso de máscara, higienização das mãos e distanciamento entre as pessoas; solicitação de materiais pelo telefone; não permissão de circulação de pessoas nos ambientes de acervo; e cancelamento da atividade semanal "Hora do Conto" (RÁDIO FANDANGO, 2020).

No que se refere ao Estado de Santa Catarina, a Biblioteca Pública de Santa Catarina, Florianópolis, além de permitir a renovação de empréstimos automáticos e sem multa, desenvolveu o "Desafio virtual de desenhos O Livro que eu Li", que voltou-se a crianças com idades entre o e 14 anos. $O$ objetivo era oferecer uma atividade lúdica durante o período de isolamento domiciliar. Foram avaliadas a qualidade artística e a fidelidade do desenho ao livro escolhido, tendo como premiação um kit de livros infantojuvenis. Para participar do concurso, cada criança deveria escolher um livro que leu durante o período de isolamento social e desenhar algo relacionado à obra (GOVERNO DE SANTA CATARINA, 2020).

A Biblioteca Pública Municipal “Luiz de Vanconcellos”, São Bento do Sul, evidenciou o atendimento ao usuário com medidas de proteção contra o Covid-19, isto é, focou na obrigação do uso de máscara e utilização de álcool em gel nas mãos por usuários e profissionais da informação; nos tapetes de entrada da biblioteca foram colocados produtos, diariamente, para que os usuários pudessem limpar seus calçados antes de entrar na instituição; acesso restrito às prateleiras; mesas e cadeiras não disponibilizadas para leitura, para que o público não permanecesse no local por muito tempo; e separação do material devolvido dos demais - materiais recebidos com luva e, posteriormente, higienizados (A GAZETA, 2020). Quanto à Biblioteca Pública Municipal Neiva Maria Andreatta Costella, Chapecó, essa passou a atender os usuários via WhatsApp, bem como ampliou o número de empréstimos por pessoa, além do prazo de devolução (FOLHA DO ESTADO SC, 2020). 


\section{CONSIDERAÇÕES DO ESTUDO}

A mudança drástica de paradigmas advinda do Covid-19 modificou os modos como as instituições atuam em sociedade. Nesse cenário, foi necessário tomar medidas de prevenção quanto ao vírus, dentre elas, o isolamento social. As bibliotecas, importantes organizações de compartilhamento de conhecimento, tiveram que adequar suas atividades a esse contexto, a fim de que, para além da pandemia, a população não sofresse com a desinformação. Nesse período, as bibliotecas púbicas foram as que mais se aproximaram da população.

Dito isso, a dúvida frequente sobre como agir em situações inesperadas alavancou o dia a dia dos profissionais da informação, que se apoiaram em medidas internacionais, advindas das áreas da Saúde e da Ciência da Informação, como UNESCO, OMS, IFLA e ALA, para desenvolverem o seu trabalho e, ao mesmo tempo, não compactuarem para com a proliferação da doença. Na amostra coletada nesta pesquisa foi possível perceber, principalmente, que as bibliotecas públicas estão disponibilizando e-books gratuitos à população em geral, independentemente de os indivíduos serem, ou não, usuários cadastrados em suas instituições. Para mais, o atendimento remoto foi enfatizado, bem como a promoção de atividades de leitura e premiação, entrega de livros a domicílio, lives, palestras online, debates online, encontros virtuais, abono de multas, indicações de livros e temas para leitura e aumento do prazo de empréstimo de recursos.

$\mathrm{Na}$ região sudeste, os Estados que mais tiveram iniciativas desse tipo, segundo o levantamento de dados realizado neste estudo, foram Minas Gerais e São Paulo, respectivamente. Já na região sul, o Estado de Santa Catarina se sobressaiu. O histórico dessas instituições traz um panorama de atuação efetiva em comunidades, com o apoio governamental e o investimento municipal para o desenvolvimento de atividades híbridas, que envolvem tanto tecnologias analógicas como digitais, em prol do desenvolvimento social.

Pode-se dizer que a atuação percebida nessas bibliotecas vai ao encontro das perspectivas do Manifesto IFLA (1994) para bibliotecas públicas, o qual preza pela criação e fortalecimento dos hábitos de leitura desde a primeira infância (atualmente, contação de histórias, lives, Clube do Livro e palestras), pelo apoio à educação individual (atualmente, cursos online, lives e palestras), pelo estímulo à imaginação e criatividade de crianças e jovens (atualmente, concursos de premiação, indicações de livros para leitura, cursos online e lives), sobretudo, assegurando que os cidadãos evoluam de forma criativa (atuação híbrida). A promoção do conhecimento sobre a herança cultural pôde ser percebida nos encontros e discussões sobre o Covid-19 em bibliotecas, o que fomentou o diálogo intercultural e permitiu que indivíduos se expressassem frente ao seu cenário de vivência.

Desse modo, muito mais do que se adequarem às novas exigências do momento, as bibliotecas públicas podem e devem se basear em documentos já publicados nas áreas da Ciência da Informação e Biblioteconomia, buscando assegurar o acesso dos cidadãos a todos os tipos de informação, em especial em momentos de pandemia, onde os indivíduos se encontram enclausurados dentro de suas casas e necessitam de informações para se conectarem ao mundo. Isto posto, a medida em que utiliza a tecnologia a seu favor, a hibridez permite que as bibliotecas ofereçam serviços adequados à públicos diferenciados, independentemente de tempo e espaço.

Como sugestão de pesquisas futuras, enfatiza-se o desenvolvimento de estudos comparativos entre o Brasil e países como os Estados Unidos da América do Norte, a 
Espanha, a Alemanha e a França, que também estão trabalhando no sentido incluir produtos e serviços para promover o atendimento híbrido em bibliotecas.

\section{FINANCIAMENTO}

Processo n 2018/03999-2, Fundação de Amparo à Pesquisa do Estado de São Paulo (FAPESP). Esta pesquisa teve a participação de um financiamento realizado pela FAPESP.

\section{REFERÊNCIAS}

A GAZETA. Livros em quarentena: biblioteca adota medidas para higienizar obras. 2020. Disponível em: http://www.gazetasbs.com.br/site/noticias/livros-emquarentena-biblioteca-adota-medidas-para-higienizar-obras-7804. Acesso em: 11 ago. 2020.

AGÊNCIA USP DE GESTÃO DA INFORMAÇÃO ACADÊMICA. Atividades em bibliotecas: limpeza, higienização e desinfecção. São Paulo: Universidade de São Paulo, 2020. Disponível em: https://www.aguia.usp.br/noticias/atividades-em-bibliotecas-limpezahigienizacao-e-desinfeccao/. Acesso em: 11 ago. 2020.

ALMEIDA JUNIOR, Oswaldo Francisco de. Bibliotecas públicas e bibliotecas alternativas. Londrina: Universidade Estadual de Londrina, 1997.

AMERICAN LIBRARY ASSOCIATION. Guidelines for reopening libraries during the Covid19. 2020. Disponível em: http://www.ala.org/advocacy/intfreedom/reopeningguidelines. Acesso em: 11 ago. 2020.

BAKER, Whitney. The hybrid conservator. Association for Library Collections \& Technical Services, v. 48, n. 3, p. 179-190, 2004. Disponível em: https://journals.ala.org/index.php//rts/article/view/5018. Acesso em: 10 jul. 2018.

BERNARDINO, Maria Cleide Rodrigues; SUAIDEN, Emir José. O papel social da biblioteca pública na interação entre informação e conhecimento no contexto da ciência da informação. Perspectivas em Ciência da Informação, v. 16, n. 4, p. 29-41, 2011. Disponível em: http://www.scielo.br/pdf/pci/v16n4/v16n4a04.pdf. Acesso em: 17 jan. 2019.

BIBLIOTECA DE PIRACICABA. Comunicado importante. Piracicaba: Prefeitura Municipal, 2020. Disponível em: http://biblioteca.piracicaba.sp.gov.br/site/. Acesso em: 11 ago. 2020.

BIBLIOTECA DE SÃO PAULO. Clube de leitura. São Paulo: Prefeitura Municipal, 2020. Disponível em: https://bsp.org.br/2020/05/05/0805-clube-de-leitura-com-novoromance-de-noemi-jaffe-abre-inscricoes/. Acesso em: 11 ago. 2020.

BIBLIOTECA DE SÃO PAULO. Clube do Audiolivro online. São Paulo: Prefeitura Municipal, 2020. Disponível em: https://bsp.org.br/2020/07/03/287-clube-doaudiolivro/. Acesso em: 11 ago. 2020. 
BIBLIOTECA DE SÃO PAULO. Curso online de Literatura Pré-Vestibular. São Paulo: Prefeitura Municipal, 2020. Disponível em: https://bsp.org.br/2020/05/07/265-cursoonline-de-literatura-pre-vestibular-inicio-2/. Acesso em: 11 ago. 2020.

BIBLIOTECA DE SÃO PAULO. Leitura ao Pé do Ouvido apresenta romance de Camilo Castelo Branco. São Paulo: Prefeitura Municipal, 2020. Disponível em: https://bsp.org.br/2020/08/07/leitura-ao-pe-do-ouvido-apresenta-romance-de-camilocastelo-branco/. Acesso em: 11 ago. 2020.

BIBLIOTECA DE SÃO PAULO. Oficina online Audiovisual para negócios. São Paulo: Prefeitura Municipal, 2020. Disponível em: https://bsp.org.br/2020/05/10/275-oficinaonline-audiovisual-para-negocios-modulo-2-inicio/. Acesso em: 11 ago. 2020.

BIBLIOTECA DE SÃO PAULO. Segundas Intenções online com Tony Belotto. São Paulo: Prefeitura Municipal, 2020. Disponível em: https://bsp.org.br/2020/07/31/38-segundasintencoes-online-com-tony-belotto/. Acesso em: 11 ago. 2020.

BIBLIOTECA DO SENADO FEDERAL. Coronavírus (Covid-19): fontes primárias de informação. Brasília: Senado Federal, 2020. Disponível em:

https://www2.senado.leg.br/bdsf/bitstream/handle/id/570174/Coronavirus_COVID19_Fontes_primarias.pdf?sequence=9\&isAllowed=y. Acesso em: 11 ago. 2020.

BIBLIOTECA MUNICIPAL DE JUNDIAÍ. Combate Covid-19. Jundiaí: Prefeitura Municipal, 2020. Disponível em: https://biblioteca.jundiai.sp.gov.br/2020/03/16/combate-covid19/. Acesso em: 11 ago. 2020.

BIBLIOTECA MUNICIPAL DE NOVA SANTA ROSA. Projeto "Semeando Leitura, Colhendo Leitores" é lançado em Nova Santa Rosa. Nova Santa Rosa: Prefeitura Municipal, 2020. Disponível em: https://agazetaweb.com/projeto-semeando-leituracolhendo-leitores-e-lancado-em-nova-santa-rosa/. Acesso em: 11 ago. 2020.

BIBLIOTECA PÚBLICA DO PARANÁ. Novo prêmio Biblioteca Digital vai selecionar livros inéditos em quatro categorias: romance, conto, poesia e infantil. Curitiba: Prefeitura Municipal, 2020. Disponível em: http://www.bpp.pr.gov.br/Noticia/Novo-PremioBiblioteca-Digital-vai-selecionar-livros-ineditos-em-quatro-categorias-Romance. Acesso em: 11 ago. 2020.

BIBLIOTECA PÚBLICA ESTADUAL DE MINAS GERAIS. Biblioteca Estadual celebra o Dia Internacional do Livro Infantil com leitura de contos pela internet. Belo Horizonte: Sistema Estadual de Bibliotecas Públicas Municipais, 2020. Disponível em: http://www.bibliotecapublica.mg.gov.br/index.php/pt-br/noticias/442-bibliotecaestadual-celebra-o-dia-internacional-do-livro-infantil-com-leitura-de-contos-pelainternet. Acesso em: 12 ago. 2020.

BIBLIOTECA PÚBLICA ESTADUAL DE MINAS GERAIS. Biblioteca estadual e clube de leitura 6.o promovem Quarentena Literária para pessoas idosas. Belo Horizonte: Sistema Estadual de Bibliotecas Públicas Municipais, 2020. Disponível em: http://www.bibliotecapublica.mg.gov.br/index.php/pt-br/noticias/468-bibliotecaestadual-e-clube-de-leitura-6-o-promovem-quarentena-literaria-para-pessoas-idosas. Acesso em: 12 ago. 2020.

BIBLIOTECA PÚBLICA ESTADUAL DE MINAS GERAIS. Live com Ozório Couto celebra Dia Nacional do Escritor. Belo Horizonte: Sistema Estadual de Bibliotecas Públicas 
Municipais, 2020. Disponível em:

http://www.bibliotecapublica.mg.gov.br/index.php/pt-br/noticias/472-live-com-ozoriocouto-celebra-o-dia-nacional-do-escritor. Acesso em: 12 ago. 2020.

BIBLIOTECA PÚBLICA ESTADUAL DE MINAS GERAIS. Sistema Estadual de Bibliotecas Públicas realiza palestra sobre saúde mental dos profissionais durante a pandemia de Covid-19. Belo Horizonte: Sistema Estadual de Bibliotecas Públicas Municipais, 2020. Disponível em: http://www.bibliotecapublica.mg.gov.br/index.php/pt-br/noticias/462sistema-estadual-de-bibliotecas-publicas-realiza-palestra-sobre-saude-mental-dosprofissionais-durante-a-pandemia-de-covid-19. Acesso em: 12 ago. 2020.

BIBLIOTECAPUBLICADOESTADORS. Biblioteca Pública do Estado do Rio Grande do Sul. Porto Alegre, 2020. Disponível em:

https://www.facebook.com/bibliotecapublicadoestadors/. Acesso em: 11 ago. 2020.

BRASIL. Ministério da Saúde. Coronavírus. Brasília: Governo Federal, 2020. Disponível em: https://www.saude.gov.br/campanhas/46452-coronavirus. Acesso em: 11 ago. 2020.

CARTA CAPITAL. Como higienizar os acervos de bibliotecas durante uma pandemia? Biblioo: Cultura Informacional, 2020. Disponível em: https://biblioo.cartacapital.com.br/como-higienizar-os-acervos-de-bibliotecasdurante-uma-pandemia/. Acesso em: 11 ago. 2020.

CAVALCANTE, Katia Viana; BRITO, Yulli Rezende; VLAXIO, Felipe. As metamorfoses da biblioteca para a Geração Z: proposta de implementação para o Espaço Cultural Bezerra de Menezes. Revista Analisando em Ciência da Informação, v. 4, n. 2, p. A03, 2016. Disponível em:

https://periodicos.ufpb.br/ojs/index.php/pbcib/article/view/36644. Acesso em: 18 jul. 2018.

CONSELHO REGIONAL DE BIBLIOTECONOMIA. Covid-19: recomendações para salvaguarda de acervos em bibliotecas. São Paulo: CRB-8, 2020. Disponível em: http://www.crb8.org.br/covid-19-recomendacoes-para-salvaguarda-de-acervos-embibliotecas/. Acesso em: 11 ago. 2020.

FIND, Soren. Change the culture: job design, work processes and qualifications in the hybrid library. IFLA Journal, v. 25, n. 4, 1999. Disponível em:

http://journals.sagepub.com/doi/pdf/10.1177/034003529902500407. Acesso em: 14 jul. 2018.

FOLHA DO ESTADO SC. Biblioteca pública segue atendimento durante pandemia. Florianópolis: Folha do Estado de Santa Catarina, 2020. Disponível em: https://www.folhaestado.com/biblioteca-pblica-segue-atendimento-durantepandemia/. Acesso em: 11 ago. 2020.

FONTAN, Jean-Marc. De l'action à la médiation culturelle: une nouvelle avenue d'intervention dans le champ du développement culturel. Cahiers de l'action culturelle, v. 6, n. 2, p. 4-14, 2007. Disponível em: http://arc.uqam.ca/upload/files/cahiers_acv6n2.pdf. Acesso: 06 out. 2020.

FREITAS, Judite; REGEDOR, António Borges. Bibliotecas públicas e cidadania activa. In: CONGRESSO NACIONAL DE BIBLIOTECÁRIOS, ARQUIVISTAS E 
DOCUMENTALISTAS, 9., 2007, Delgada. Anais eletrônicos... Delgada: BAD, 2007. p. 117. Disponível em:

https://www.bad.pt/publicacoes/index.php/congressosbad/article/view/517/284.

Acesso em: 24 nov. 2018.

GIL, Antônio Carlos. Como elaborar projetos de pesquisa. São Paulo: Atlas, 2008.

GARCEZ, Eliane Maria Stuart; RADOS, Gregório Jean Varvakis. Biblioteca híbrida: um novo enfoque no suporte à educação a distância. Ciência da Informação, v. 31, n. 2, 2002. Disponível em:

https://www.scielo.br/scielo.php?script=sci_abstract\&pid=S0100-

$19652002000200005 \&$ Ing=en\&nrm=iso\&tlng=pt. Acesso em: 14 jul. 2018.

GOVERNO DE SANTA CATARINA. Coronavírus em SC: biblioteca pública promove concurso virtual de desenho para crianças. 2020. Disponível em:

https://www.sc.gov.br/noticias/temas/coronavirus/coronavirus-em-sc-biblioteca-

publica-promove-concurso-virtual-de-desenho-para-criancas. Acesso em: 11 ago. 2020.

GOVERNO DO ESPÍRITO SANTO. Campanha Quarentena Literária promove incentivo à leitura no Estado. 2020. Disponível em: https://www.es.gov.br/Noticia/campanhaquarentena-literaria-promove-incentivo-a-leitura-no-estado. Acesso em: 11 ago. 2020.

GOVERNO DO ESPÍRITO SANTO. I Encontro Estadual de Bibliotecas Públicas Municipais: 2020 será realizado por videoconferência. 2020. Disponível em:

https://www.es.gov.br/Noticia/i-encontro-estadual-de-bibliotecas-publicas-municipais2020-sera-realizado-por-videoconferencia. Acesso em: 11 ago. 2020.

GRUPO DE INFORMAÇÃO E DOCUMENTAÇÃO JURÍDICAS DO DISTRITO FEDERAL. Preparação das bibliotecas ante ao Coronavírus. Distrito Federal: GIDJ, 2020. Disponível em: http://abdf.org.br/gidj/noticias/item/46-preoparacao-bibliotecas-corona-virus. Acesso em: 11 ago. 2020.

INTERNATIONAL FEDERATION OF LIBRARY ASSOCIATIONS AND INSTITUTIONS. Covid-19 and the global library field. 2020. Disponível em: https://www.ifla.org/covid19-and-libraries. Acesso em: 11 ago. 2020.

INTERNATIONAL FEDERATION OF LIBRARY ASSOCIATIONS AND INSTITUTIONS. Manifesto IFLA/UNESCO sobre bibliotecas públicas. 1994. Disponível em: http://archive.ifla.org/VII/s8/unesco/port.htm. Acesso em: 30 set. 2018.

INTERNATIONAL FEDERATION OF LIBRARY ASSOCIATIONS AND INSTITUTIONS. Manifesto IFLA sobre transparência, bom governo e combate a corrupção. 2008. Disponível em: http://www.ifla.org/publications/iflamanifesto-on-transparency--goodgovernance-and-freedom-fromcorruption. Acesso em: 14 nov. 2018.

JORNAL DO COMÉRCIO. Por conta da pandemia de coronavírus, Biblioteca Pública de Erechim registra maior procura por livros. Jornal do Comércio, 2020. Disponível em https://www.jornaldocomercio.com/_conteudo/jornal_cidades/2020/04/736271-porconta-da-pandemia-de-coronavirus-biblioteca-publica-de-erechim-registra-maiorprocura-por-livros.html. Acesso em: 12 ago. 2020.

KEINART, Tania Margarete Mezzomo. Administração pública no Brasil: crises e mudanças de paradigmas. São Paulo: Annablum; FAPESP, 2000. 
MARQUINA, Julián. 7 medidas a serem consideradas para criar um protocolo de ação ao reabrir as bibliotecas. 2020. Disponível em:

https://drive.google.com/file/d/1Vodl6zatznStmngBVRAkTjL8x1Q6CWJB/view. Acesso em: 11 ago. 2020.

MORO, Eliane Lourdes da Silva; ESTABEL, Lizandra Brasil; BEHR, A. Gestão em bibliotecas. In: MORO, Eliane Lourdes da Silva; ESTABEL, Lizandra Brasil. Biblioteca: conhecimentos e práticas. Porto Alegre: Penso, 2014. p. 57-76.

NASSAR, Paulo. A mensagem como centro de relacionamentos. In: Di Felice, Massimo. Do público para as redes: a comunicação digital e as novas formas de participação social. São Caetano do Sul: Difusão Editora, 2008. p. 191-202.

WEBER, M. A virtual subject library for Library and Information Science: unnecessary or overdue?. Information-Wissenschaft und Praxis, v. 55, n. 2, p. 89-94, Mar. 2004.

ORERA-ORERA, Luisa. The university library in the context of the new social and educational model. Profesional de la Informacion, v. 16, n. 4, p. 329-337, 2007. Disponível em: https://search.proquest.com/docview/57702579?accountid=8112. Acesso em: 04 maio 2018.

ORERA-ORERA, Luisa; PACHECO, Federico Hernández. El desarrollo de coleciones em bibliotecas públicas: fundamentos teóricos. Investigación Bibliotecológica, v. 31, n. 71, 2017.

ORGANIZAÇÃO DAS NAÇÕES UNIDAS PARA A EDUCAÇÃO, A CIÊNCIA E A CULTURA. Ações para apoiar a mídia, ampliar o acesso à informação e alavancar o uso de tecnologias digitais na luta contra a pandemia. 2020. Disponível em:

https://pt.unesco.org/covid19/communicationinformationresponse/mediasupport.

Acesso em: 12 ago. 2020.

ORGANIZAÇÃO MUNDIAL DA SAÚDE. Coronavirus desease (COVID-19) pandemic. 2020. Disponível em: https://www.who.int/emergencies/diseases/novel-coronavirus2019?gclid=CjwKCAjwps75BRAcEiwAEiACMe3elNgbCeBN2vmNmWhxk3C9zpEvJzqS nILd2el6oTpiRrEDFLmoBoC3OAQAvD_BwE. Acesso em: 12 ago. 2020.

PREFEITURA DE LINHARES. Coronavírus: biblitoeca funcionará apenas para empréstimo e devolução de livros. Linhares: Prefeitura Municipal, 2020. Disponível em: https://linhares.es.gov.br/2020/05/05/coronavirus-biblioteca-funcionara-apenaspara-emprestimos-e-devolucao-de-livros/. Acesso em: 12 ago. 2020.

PREFEITURA DO RIO DE JANEIRO. Prefeitura oferece série de opções online para garantir acesso da população à leitura. Rio de Janeiro: Prefeitura Municipal, 2020. Disponível em: https://prefeitura.rio/cultura/prefeitura-oferece-serie-de-opcoesonline-para-garantir-acesso-da-populacao-a-leitura/. Acesso em: 13 ago. 2020.

RÁDIO FANDANGO. Biblioteca Pública Municipal “Doutor João Minssen”. 2020. Disponível em: https://www.radiofandango.com.br/2020/05/18/biblioteca-publicaarquivo-historico-atelier-municipal-retomam-atendimento-nesta-terca-feira/. Acesso em: 12 ago. 2020.

RÁDIO SANTA CRUZ. Pará de Minas em destaque: setor cultural vai venccendo o distanciamento com muita criatividade. 2020. Disponível em: 
https://www.radiosantacruzfmg.com.br/acontece/noticia/60013. Acesso em: 12 ago. 2020.

SILVA, Rafaela Carolina da. Gestão de bibliotecas públicas no contexto híbrido: um estudo comparativo de bibliotecas híbridas no âmbito nacional e internacional em prol do desenvolvimento de comunidades. 2017. Dissertação (Mestrado em Ciência da Informação) - Faculdade de Filosofia e Ciências, Universidade Estadual Paulista "Júlio de Mesquita Filho", Marília. Disponível em: https://repositorio.unesp.br/handle/11449/150798. Acesso em: 31 jul. 2017

SILVA, Rafaela Carolina da; JORENTE, Maria José Vicentini; CALDAS, Rosângela Formentini. Integração da competência em informação no contexto das bibliotecas vivas. Revista Ibero-Americana de Ciência da Informação, v. 10, n. 2, p. 275-294, 2017. Disponível em: https://periodicos.unb.br/index.php/RICl/article/view/2541. Acesso em: 18 jul. 2020.

SILVA, Rafaela Carolina da; OTTONICAR, Selma Letícia Capinzaiki; CALDAS, Rosângela Formenini; CASTRO FILHO, Cláudio Marcondes de. A competência em informação e o comportamento informacional dos usuários de bibliotecas híbridas: um estudo comparativo no Brasil e na Escócia. Informação \& Informação, v. 23, n. 1, p. 398-423, 2018.]. Disponível em:

http://www.uel.br/revistas/uel/index.php/informacao/article/view/30906. Acesso em: 15 jul. 2020.

SISTEMA NACIONAL DE BIBLIOTECAS PÚBLICAS. Orientações a bibliotecas públicas $e$ comunitárias Covid-19. 2020. Disponível em: https://ibict.br/sala-deimprensa/noticias/item/2112-coronavirus-e-residuos-solidos-como-lidar-com-a-questaoem-tempos-de-pandemia. Acesso em: 11 ago. 2020. 